\title{
Megalouretra asociada a Síndrome de VACTER
}

\author{
Romero Otero J.*, Gómez Fraile A, Feltes Ochoa J*, Blanco Carballo O*; Aransay Bramtot A, \\ López Vázquez F, Alonso L**.
}

\begin{abstract}
Sección de Urología Pediátrica. *Servicio de Urología. Hospital Universitario 12 de Octubre. Madrid. **Servicio de Cirugía Pediátrica del HUCM. Las Palmas de Gran Canaria (Canarias).
\end{abstract}

Actas Urol Esp 2006; 30 (4): 412-414

\section{RESUMEN}

\section{MEGALOURETRA ASOCIADA A SÍNDROME DE VACTER}

La megalouretra es una malformación congénita muy poco frecuente. Se produce como consecuencia de la falta de desarrollo del cuerpo esponjoso y en ocasiones también de los cuerpos cavernosos. Es frecuente su asociación con otras malformaciones del tracto urinario, y con el síndrome de Prune Belly. Presentamos un caso excepcional por su asociación con síndrome de VACTER y estenosis de uretra bulbar.

Palabras clave: Megalouretra, Síndrome de VACTER. Megauretra. Cuerpo esponjoso.

\section{ABSTRACT}

\section{MEGALOURETHRA IN ASSOCIATION WITH VACTER SYNDROME}

The megalourethra is an uncommon congenital anomally. It is a consecuence of the abnormal development of the corpus spongiosum and, occasionally, also the abnormal development of the corpora cavernosum. It is specially common in association with the Prune-Belly syndrome, and with upper tract abnormalities. We present a bizarre case because of its association with a VACTER syndrome.

Keywords: Megalourethra. VACTER Syndrome. Megauretra. Corpus spongiosum.

$\mathrm{L}^{\mathrm{a}}$ a megalouretra es una malformación congénita consistente en un alargamiento de la uretra pendular sin evidencia de obstrucción distal. Es muy poco frecuente y se relaciona con la falta de desarrollo del cuerpo esponjoso y en ocasiones también de los cuerpos cavernosos. Es frecuente su asociación con el síndrome de Prune Belly y con otras malformaciones del tracto urinario superior. Presentamos un caso excepcional de megalouretra asociado a síndrome de VACTER con estenosis de uretra bulbar.

\section{CASO CLÍNICO}

Un recién nacido varón, con $\mathrm{S}$. de VACTER consistente en: hemivértebras, Atresia de Esófago, Megauréter bilateral con Megalouretra y Comunicación Interauricular; a los 6 días de vida se intervino de Atresia de Esófago, y en el posto- peratorio presentó un cuadro de Insuficiencia Renal Aguda (IRA), que precisó la colocación de una cistostomía suprapúbica y tratamiento médico adecuado. El proceso evolucionó satisfactoriamente por lo que se retiró la misma.

El niño fue trasladado a nuestro centro, a los 7 meses de vida, para tratamiento de sus anomalías urológicas. En la exploración física destacaba: buen estado general; el cráneo y ORL dentro de la normalidad; el tórax presentaba cicatriz de toracotomía postero-lateral derecha. El abdomen era blando y globuloso, se palpaban masas en ambos flancos, que parecían corresponder a los riñones. En los genitales se evidenció en la cara ventral del pene una masa blanda, con integridad de cuerpos cavernosos, que correspondía a la uretra peneana alargada y agrandada. El meato uretral era hipospádico y de gran tamaño (Fig.1). 


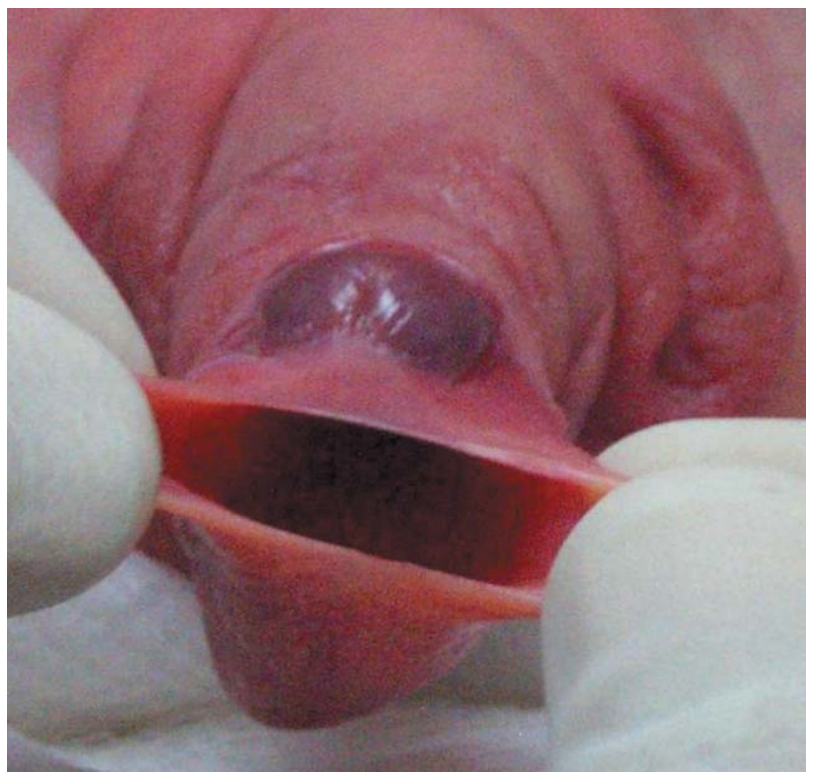

FIGURA 1. Aspecto macroscópico de pene con megauretra. Se evidencia el aspecto de meato uretral de gran diámetro.

Las pruebas complementarias mostraban: un hemograma y estudio de coagulación dentro de la normalidad; la bioquímica presentaba como único parámetro alterado la creatinina $(2,6$ $\mathrm{mg} / \mathrm{dl})$. En la Ecografía se visualizaron ambos riñones con las corticales adelgazadas y mala diferenciación córtico-medular; existía ureterohidronefrosis bilateral grado IV, más acusada en el lado derecho, y una vejiga de amplia capacidad. La cistouretrografia miccional seriada (CUMS) evidenció gran dilatación de la uretra peneana, tipo escafoideo (Fig. 2), hasta una zona estenótica a nivel de uretra bulbar de pequeño calibre, que permitía el paso de contraste a vejiga, gracias a lo cual se pudo objetivar que la vejiga era de buen tamaño, la existencia de un divertículo paraureteral derecho y de reflujo vésico-ureteral grado V/V del mismo lado. El DMSA mostraba un parénquima renal adelgazado, principalmente en el lado derecho, con función relativa del 7\% para esa unidad y del 93\% para la contralateral. Decidimos en primer lugar efectuar cistoscopia, visualizando la uretra distal dilatada, la mucosa parecía de aspecto normal y existía una estenosis a nivel de uretra bulbar infranqueable. Motivo por el que se procedió a la realización de uretrotomía endoscópica y paso de una sonda $8 \mathrm{Fr}$, que se exteriorizó por una vesicostomía que se practicó al mismo tiempo. Durante los 3 meses siguientes se efectuaron cambios periódicos de sonda cada 20 días. Al final de este periodo se hizo un nuevo control cistoscópico en el que se evidenció recidiva de la estenosis, menos severa que la previa. Practicamos una nueva uretrotomia, y dejamos emplazada una sonda tutor de 8Fr. Durante los seis meses siguientes se mantuvo el calibre uretral con dilataciones uretrales y cambios de sonda mensuales. En un tercer tiempo, a los 19 meses de edad, se constató la no existencia de estenosis uretral, por lo cual decidimos la reconstrucción uretral de la megauretra. Se procedió a la realización de uretroplastia con reducción del tamaño uretral, resecando parcialmente las paredes laterales y anterior, y dejando sonda - tutor uretral del 8Fr. Elongamos los tejidos periuretrales para unirlos en líneas laterales, evitando la línea media, permitiendo un buen soporte de la pared uretral anterior ante la falta de cuerpo esponjoso. Al mes retiramos la sonda-tutor y comprobamos su buen calibre. Actualmente el niño presenta buen estado, con inicio de micciones, estando pendiente de cierre de la vesicostomía.

\section{DISCUSIÓN}

El término megalouretra fue empleado por primera vez por Nesbit ${ }^{1}$. Se utiliza para referirse a una entidad rara, consistente en la dilatación no

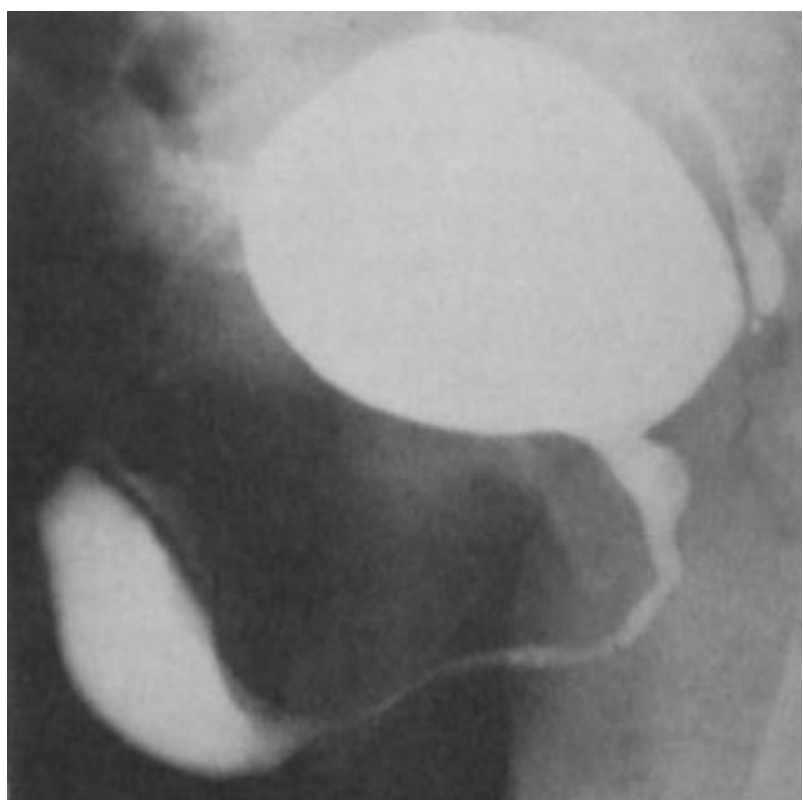

FIGURA 2. Cistouretrografia retrógrada en la que se evidencia una uretra anterior de gran tamaño, junto con estenosis uretral bulbar. 
obstructiva de la uretra ${ }^{2}$. Existe falta de desarrollo del cuerpo esponjoso y en ocasiones se asocia este mismo defecto en los cuerpos cavernosos. Se clasifican en escafoidea, en el primero de los supuestos, y fusiforme en el segundo ${ }^{2}$.

Se desconoce con exactitud cual es el defecto embriológico que determina su aparición, pero para Stephens y Fortune $^{3}$ pueden existir dos teorías que lo justifiquen: un defecto de canalización del cordón epidérmico que da origen a la uretra distal, y así se produciría temporalmente una obstrucción y dilatación del tracto urinario ${ }^{4}$; o un retraso en la evolución de los tejidos mesenquimales que formarian la uretra y se produciría su compresión y distensión impidiendo el desarrollo del cuerpo esponjoso y en ocasiones de los cavernosos. Para Misseri et al. ${ }^{5}$ la primera teoría sería la válida. Existe posibilidad de que sea un defecto en la canalización de la uretra glandal que está apoyada por la asociación habitual con el hipospadias coronal, como ocurrió en el caso nuestro.

La megalouretra se asocia frecuentemente con el Síndrome de Prune Belly ${ }^{6}$, que se caracteriza por la ausencia o hipoplasia de la musculatura abdominal anterior, asociado a vejiga hipocontráctil y a criptorquidia bilateral, puede haber otras manifestaciones sistémicas sobre todo pulmonares o cardiacas. En nuestro caso se asoció a Sindrome de VACTER ${ }^{7}$ siendo poco frecuente y minimamente referido en la literatura. El síndrome se caracteriza por la afectación vertebral, anomalía anal, anomalía cardiaca, anomalía traqueo-esofágica y renal (sus iniciales forman el nombre del sindrome). Es un defecto genético que no está clara su etiología.
La megalouretra se diagnostica por la apariencia física del pene, deformado, con piel redundante y aspecto de masa, que aumenta de tamaño con la micción. Siempre se debe hacer un estudio completo, no solo urinario, por si existiesen otros defectos congénitos asociados.

La corrección quirúrgica consiste en la uretroplastia reductora en el tipo escafoides, como en el nuestro, pero se ha de tener en cuenta si existen otras anomalías asociadas, que puedan tener prioridad en su tratamiento. El tipo fusiforme es más difícil tratarlo debido al déficit, además, de los cuerpos cavernosos. Lo más frecuente es tener que efectuarlo de forma escalonada debido a la asociación de otras patologías.

\section{REFERENCIAS}

1. James E.A., Freedman A.L, Ehrlich R.M., FAAP, FACS: Megalourethra and urethral diverticula. Urol Clin N Am 2002;(29):341-348.

2. Gonzalez J.E., posterior urethral valves and other urethral anomalies, Campbell 8 ed., chapter 63, page 2227.

3. Stephens S. H. And Fortune D.W.: Pathogenesis of megalourethra. J Urol 1993;149:1512-1516.

4. Stephens S.H. and Webster R.: Congenital malformations of the rectum, anus and genitourinary tracts. London: Churchil Livingstone, 1963, p.226.

5. Misseri R., Cain M.P., Albernathy M.P., Bradbury C. and Padilla L.M.: Megalourethra mimicking an anterior abdominal wall mass. J. Urol. 2004 October;(172):1454-1455.

6. Smith A., Woodard J.R.: Prune Belly syndrome, Campbell 8 ed., chapter 60, page 2117-2135.

7. Baver S.B., Koff S. A., Jayanthi V.: Voiding disfunction in children, Campbell 8 ed., chapter 64, page 2250.

8. Dorairajan T. Defects of spongy tissue and congenital diverticula of penile urethra. Aust. N.Z.J. Sur. 1963;32:209-214.

Dr. J. Romero Otero

E-mail: jromerootero@yahoo.es

(Trabajo recibido el 21 de septiembre 2005) 